\title{
Negative Emotion in Music: What is the Attraction? A Qualitative Study
}

\author{
SANDRA GARRIDO \\ University of New South Wales \\ EMERY SCHUBERT \\ University of New South Wales
}

\begin{abstract}
Why do people listen to music that evokes negative emotions? This paper presents five comparative interviews conducted to examine this question. Individual differences psychology and mood management theory provided a theoretical framework for the investigation which was conducted under a realist paradigm. Data sources were face-to-face interviews of about one hour involving a live music listening experience. Thematic analysis of the data was conducted and both within-case and cross-case analyses were performed. Results confirmed the complexity of variables at play in individual cases while supporting the hypothesis that absorption and dissociation make it possible for the arousal experienced when listening to sad music to be enjoyed without displeasure. At the same time, participants appeared to be seeking a variety of psychological benefits such as reflecting on life-events, enjoying emotional communion, or engaging in a process of catharsis. A novel finding was that maladaptive mood regulation habits may cause some to listen to sad music even when such benefits are not being obtained, supporting some recent empirical evidence on why people are attracted to negative emotion in music.
\end{abstract}

Submitted 2012 February 12; accepted 2012 June 2.

KEYWORDS: music, emotion, negative valence, absorption; rumination

WHY do we enjoy "a good cry"? It seems counter-intuitive that people would willingly seek out music or other aesthetic experiences that make them cry when we do our best to avoid things that make us cry in "real life" (Vingerhoets et al., 2001). Emotions that are generally perceived as "negative" are usually associated with unpleasantness (Colombetti, 2005). This is a paradox which has puzzled philosophers since at least the time of Aristotle. Yet, despite the centuries of discussion, philosophers have reached little consensus on the issue.

Their arguments can be broadly divided into that of cognitivists and emotivists. Cognitivists such as Kivy (2002) argue that we do not actually experience "garden-variety" emotions as expressed in the music, but rather perceive them within the structure of music. Emotivists, on the other hand, although differing according to detail, agree that there is some connection between the emotions expressed by the music and those experienced by the listener (Levinson, 1996, Robinson, 1994).

Much of this discussion between cognitivists and emotivists appears to hinge on their respective definitions of emotion leading to disagreement over whether people actually feel sad when listening to sad music (Garrido and Schubert, 2010). In fact there may be no single answer. Rather a complex interplay of factors may be involved in the case of each unique individual.

Thus, the current research will attempt to investigate individual differences in enjoyment of "sad" music, and some of the personality factors that may be involved. This investigation will include looking at both motivations for seeking out sad music, and the cognitive mechanisms that may make it possible to enjoy the experience of negative emotions in an aesthetic context. The current study consists of a detailed qualitative analysis of a small sample of individuals who were selected on the basis of their self-reported attraction to music expressing negative emotions, and thus provide information-rich examples of the phenomenon of interest. 


\section{THEORETICAL FRAMEWORK}

The starting point for this research involves two important lines of argument. The first is that of individual differences psychology and the second entails an examination of mood management theory and arousal. These two areas will be examined briefly below along with a description of how they form the basis of this research.

\section{Individual Differences Perspective}

The study of individual differences, which encompasses personality, has been a significant part of psychology for more than a century (Chamorro-Premuzic, 2007). It could be defined as the science of describing how persons differ (Westen, 2002). An important assumption in the individual differences perspective is that to understand the complexity of human behaviour and experiences it is necessary to study the differences between them (Goldberg, 1993).

There is some evidence that individual differences influence listening preferences as well as emotional response to music. Litle and Zuckerman (1986), for example, found that high scores in sensation-seeking were correlated to a preference for highly stimulating music such as rock. ChamorroPremuzic and Furnham (2007) also found that intellectually engaged individuals with higher IQs tended to use music in a different way to neurotic, introverted and non-conscientious individuals. Other studies have discussed gender related differences in response to music (Kreutz et al., 2008, Altenmueller et al., 2002). In relation to sad music, our earlier research (Garrido and Schubert, 2011) discovered significant correlations between absorption, "music empathy," and a liking of sad music.

Given the evidence that personality has a significant impact on listening habits and emotional response to music, it follows that individual differences are also key to understanding the attraction to negative emotion in music.

\section{Mood Management Theory and Arousal}

The theory of mood management (Zillmann, 1988, Knobloch and Zillmann, 2002) predicts that individuals will choose music based on a desire to diminish a bad mood or to perpetuate a good mood (Zillmann, 1988, p. 328). In general this would mean that individuals will choose music that brings them pleasure, or that expresses positive and uplifting emotions. At other times, long-term benefits may override immediate hedonistic desires, e.g., in order to deal with certain negative emotions such as regret (Nabi et al., 2006).

Whether an individual perceives certain music as pleasurable or not may have to do with the concept of arousal. Arousal is notoriously difficult to define and not always used consistently within the literature. In everyday terms, to be aroused means to be wide awake, alert, vigorous, excited, and full of pep (Thayer, 1989). At times it is used to refer to physiological arousal, or activation of the autonomic nervous system (Juslin and Vastfjall, 2008). Others refer to it as a "continuum of sensitivity to environmental stimuli" ranging from sleeping to various waking states (Berridge, 2008).

Some theorists describe arousal as part of a two-dimensional model of emotion (Russell, 1979) the other dimension being valence. According to these models, sadness would be an emotion of low arousal and negative valence. However, this is an overly simple model (Fontaine et al., 2007). Thayer (1978) argues that arousal itself is multidimensional. He posits that arousal or activation consists of at least two dimensions which he calls "energetic/sleepy" and "tense/placid." Thus positive moods may have heightened energy and be thus considered high in arousal, or may involve reduced tension and are thus low in arousal. According to this view a single emotion can be both high and low in arousal. Therefore, Benjafield (1997) defines arousal as "the intensity with which an emotion is experienced...for example, one can be more or less happy, more or less angry, more or less disgusted. Arousal refers to how strongly an emotion occurs, regardless of what emotion it is" (p. 366).

Arousal may also involve higher levels of neural activity. Duffy (1962), in her activation theory, argues that arousal is synonymous with brain activity in the reticular formation and the cortex. Martindale (1988) also speaks about "activation." Expanding on Berlyne's psychobiological theory (1972), he proposes that neural activation is intrinsically pleasurable and that the amount of pleasure a particular stimulus will invoke depends upon the number of "cognitive units" or neural networks it activates 
(Martindale and Moore, 1988). Thus music may have the potential to influence arousal levels and thus pleasure by affecting both the intensity of emotion and the amount of neural activation experienced.

What level of arousal is pleasant for the individual depends on several factors. The "optimal stimulation theory," based on the work of Berlyne and others (Fiske and Maddi, 1961, Berlyne, 1972, Duffy, 1962) assumes that for each individual there is an ideal level of arousal that is most comfortable and productive. Both under-stimulation and over-stimulation can be unpleasant, and therefore an individual will seek to optimise his level of arousal (Zentall and Zentall, 1983). The level most comfortable to an individual and the type of stimuli they will choose to achieve this can vary depending on factors such as the intelligence of the individual, whether they are introverted or extroverted, and how much stimulation they are experiencing at the time of listening within their environment (Rentfrow and Gosling, 2003, ChamorroPremuzic and Furnham, 2007).

When it comes to music evoking negative emotions, Schubert (1996) provides an explanation of the mechanism that may be involved. He argues that when negative emotions are activated in an aesthetic context, a "dissociation node" is triggered which inhibits displeasure centres. Thus the arousal produced by the negative emotions can be experienced without the usual accompanying displeasure. This bears some resemblance to the way victims of extremely traumatic events "dissociate" or detach themselves from reality as a coping mechanism (Van Ijzendoorn and Schuengel, 1996). Less extreme forms of dissociation occur in non-clinical populations as absorption, which enables a person to temporarily set aside reality while engaged in something else (Eisen and Lynn, 2001). There is also some evidence of a connection between imagination and fantasy-proneness with a tendency to dissociate (Garrido and Schubert, 2010).

Our earlier work has demonstrated a significant positive relationship between enjoyment of negative emotion in response to music and absorption (Garrido and Schubert, 2011). For those with strong tendencies toward dissociation or absorption, negative emotions evoked by music can therefore be experienced without displeasure. Thus, listening to sad music falls within mood management theory whether the motivations for listening are immediately hedonistic or for longer-term benefits.

While pleasure-seeking or mood management may motivate the listening choices of some people, there may also be some whose purpose is not quite so rational. Certain maladaptive thinking patterns may also be predictors of an attraction to sad music. Some individuals may be attracted to sad music despite the fact that it perpetuates their dysphoria. Habitual ruminators and those suffering from clinical or undiagnosed depression appear to have an involuntary bias towards negative stimuli and therefore provide an exception to mood management theory (Garrido, 2009).

\section{Aims of the Current Research}

The current research will attempt to integrate the theoretical perspectives discussed above into a single framework for investigation. In line with individual differences psychology, this study proposes to examine the individual personality traits and the interaction between them that may have an influence on whether a person enjoys negative emotion in music or not at a phenomenological level. The concepts of mood management and arousal were used as a basis for discovering the extent to which individuals may use sad music as a tool for emotional regulation.

\section{RESEARCH DESIGN \& METHOD}

This research was conducted under a realism paradigm. Realism research assumes that human experience is only a part of reality and that objective reality is not easily understood or measured (Wynn and Williams, 2008). Thus the current research was carried out with the understanding that while the participants do not necessarily have conscious access to their own cognitive mechanisms, their perceptions can provide us with some evidence and a "window" through which to view external reality (Sobh and Perry, 2006).

A further assumption, in line with both the realism paradigm and individual differences psychology, is that the research is unlikely to yield a single answer to the paradox. Rather it is likely that it will identify "patterns in experiences" resulting in a "family of answers" (Sobh and Perry, 2006, p.1200). The varying temperaments, life-circumstances and strategies for managing their moods that individuals have will likely result in different stories being told about their music-listening habits. 


\section{The Sample}

Realism researchers use their conceptual framework developed from a knowledge of the literature in assisting them to select interviewees (Sobh and Perry, 2006). In this research, it was assumed that people who have a strong emotional response to music and especially music expressing negative emotions should provide information-rich examples of the personality traits and thought processes involved. For replication purposes it is also useful to choose cases where the results are expected to be similar or contrary for predictable reasons (Yin, 1994). Therefore several participants from an earlier study (Garrido and Schubert, 2011) were selected for the current study based on the strength of their professed emotional response to music, and/or their enjoyment of music expressing negative emotions. An invitation to participate in the current study was sent by email.

The five participants were aged from 19 to 46 (see Table 1). Of the five, two participants were male and all but one were from non-English speaking backgrounds. However, the study took place within an English language context in Australia in a variety of settings which were chosen by the participants. Music recordings were played on iPods brought to the interview by the participants.

\begin{tabular}{|l|l|l|}
\hline $\begin{array}{l}\text { Participant } \\
\text { Number }\end{array}$ & Age & Gender \\
\hline P1 & 23 & F \\
\hline P2 & 25 & M \\
\hline P3 & 40 & F \\
\hline P4 & 19 & F \\
\hline P5 & 46 & M \\
\hline
\end{tabular}

Table 1. Profile of Participants.

\section{Data Collection Procedure}

The five participants all took part in an interview which included an on-the-spot listening experience, rather than just asking participants to remember their responses when listening to the music in the past. Participants were asked to bring recordings of music to which they had a strong emotional response. They were not specifically asked to bring music evoking negative emotions in order to minimise the effect of demand characteristics. The recordings were then played within the interview so that the subjects would have the benefit of immediacy in describing their emotional response and thoughts. Previous studies have played pre-determined excerpts for the participants (see for example Konecni et al., 2008). However the decision was made in this study to allow participants to bring music of their own choice because of the potential influence of genre preference and familiarity (Schubert, 2007).

Following the playing of the music chosen by the participant, they were asked several questions as to their experiences while listening. The aim was to find out how the listeners themselves described their experience; what thoughts or feeling arose while listening; how the emotions they experienced compared to what they perceive the music to be expressing; and, how the emotions experienced compared to emotions induced by "real-life situations."

Subsequent to the listening experience, participants were interviewed about their broader listening habits and emotional response to music. These interviews were conducted using a general guide approach (Britten, 1995). The interview guide was developed based upon the theoretical framework drawn from a study of the literature (Sobh and Perry, 2006). Care was taken with the wording of questions so as not to influence the response of the subjects unduly. It was also considered important for purposes of triangulation to ask the different interviewees the same questions in order to test the similarity of their perceptions. However the actual stream of questions was intended to be fluid rather than rigid, so as to allow the subject to speak at length. Open questions were used so as to uncover any areas that were missing from the initial conceptual framework (Sobh and Perry, 2006). 
Demographic questions were left until the end of the interview so that the interviewee did not become primed to provide short-answer routine responses (Patton, 1990, p. 295). Instead, some general "warm-up" questions designed to encourage the interviewee to talk at length about music were used to begin the interview.

The interviewer then attempted to find out what kinds of music the participants preferred to listen to and in what situations. These topics were discussed in relation to music in general, but particularly in relation to music expressing negative emotions. Specifically, participants were asked to recall a piece of music that they would describe as "sad," whether they liked the piece or not and what they would feel and think about while listening to it. It was not expected that subjects would have access to the cognitive processes involved. Rather the study was expected to reveal how the listener themselves perceived their experience. In addition, based on our earlier research regarding the correlation between an enjoyment of negative emotions in music and dissociation/absorption and other characteristics (Garrido and Schubert, 2011), participants were asked several questions relating to personality traits. In particular the traits of empathy, imagination, absorption and rumination were discussed. Although our previous study used several published inventories to assess these traits (Glisky and Kihlstrom, 1993, Trapnell, 1997, Davis, 1983), the present investigation aimed to encourage free response although guiding the participant in a general discussion of the characteristics of interest. It was considered inappropriate to explicitly mention the traits, or to use the inventories that assess them because of the open-ended nature of the questionnaire.

The last question asked if there was anything that the interviewee thought relevant which they would like to add, as recommended by Sobh and Perry (2006). Both the interview and the listening experience responses were digitally recorded and transcribed before analysis.

\section{Data Analysis}

Thematic analysis was used for examination of the narratives collected during the interviews. Thematic analysis is "a method for identifying, analysing and reporting patterns (themes) within the data" (Braun and Clarke, 2006, p. 79). Themes are defined as units derived from patterns such as "conversation topics, vocabulary, recurring activities, meanings, feelings or folk sayings and proverbs" (Taylor and Bogdan, 1998, p. 143). Braun and Clarke (2006) argue that thematic analysis can be applied across a broad range of theoretical and epistemological approaches. This theoretical freedom provides a flexible and useful research tool which can potentially provide a rich and detailed, yet complex, account of data. This study followed the procedure for thematic analysis outlined by them.

First, the recorded data were transcribed as described by Braun and Clarke (2006) and loaded into the NVivo 8 software program for analysis. After reading through the material initial ideas were noted. Next, the data were systematically allocated to the chosen codes (Miles and Huberman, 1994).

The initial codes chosen in this research were based on the theoretical framework and the general topics that were covered in the interview guide (Sobh and Perry, 2006). Additional codes were added during the data-collection procedure and transcription process. Initially the data were coded under the topics: source of emotional response to music; purposes for music listening; mood regulation; and, music evoking negative emotions (See Table 1).

Once the data had been sorted according to these codes, the patterns were analysed and combined to create themes and sub-themes (see Table 2). The data under each theme was then subjected to both within-case analysis and cross-case analysis (Patton, 1990). The latter is particularly useful for understanding underlying structures and mechanisms (Yin, 2009).

\section{RESULTS AND DISCUSSION}

\section{The Listening Experience}

The participants chose a diverse range of pieces to play during the interview, including jazz, classical, rock, hip-hop and country. In three out of the five cases, participants were not aware of the name of the piece they had chosen or the composers or performers, since the music had been downloaded from the internet based on their attraction to the sound alone. Two of the five pieces were partially identified.

One of the pieces chosen by Participant 1 (P1) to listen to during the interview was a sad love song with lyrics in Japanese. Although the participant does not understand Japanese it had special significance 
for her because of the memories associated with it. Mostly she would avoid listening to this song because she does not want it to lose meaning for her. Interestingly, she described her response to the music as being a physical response in the beginning, which she then attributed to her understanding of the emotional associations with this piece of music. Other music that does not have the same mental associations for her may still cause a similar physical reaction but to a lesser degree. A second piece of music discussed with the participant is also something that she normally avoids listening to. It causes her to feel uncomfortable because she associates it with the unstable mental state of an acquaintance who committed suicide.

The preferred music choices of Participant 2 (P2) were hip-hop and R \& B, an example of which was listened to during the interview. He claimed not to be aware of the lyrics when listening to hip-hop music but to mostly enjoy the beat. He stated that the content of the lyrics did not have any influence on him and do not make him feel more aggressive. He also played an example of slow instrumental jazz music which he listens to when he wants to relax.

The piece chosen by Participant 3 (P3) was sung by Johnny Cash and had a slow, calm tempo. The participant reported that she is usually attracted to this type of deep male voice which, to her, portrays warmth. She described this music as communicating the message: "don't worry about the small stuff and try and be happy." She listens to this music when feeling down because it makes her feel better. However, she also reported feeling a little bit sad on one level when listening to it. She attributed this to the complexity of human emotion; the fact that humans can feel sad and happy at the same time, and that there tends to be an element of sadness in any happiness.

Participant 4 (P4) chose a solo piano piece which caused her to feel "safe but sad" at the same time. The feeling of sadness appeared to be mostly of a physiological nature which again is not connected to any particular thought or memory. The feeling of safety was attributed to the simplicity of the music; the fact that she can imagine someone's hands playing the music and because the emotions expressed make sense to her. The music appeared to give her an acceptable way in which to experience her own mood changes. However, this music is not something she would listen to often. In fact she explained that when she wants to get out of a low mood she would listen to something more cheerful. In addition to her changeable moods, the participant attributed her attraction to this type of music to her reflectiveness and a tendency to "over-think."

At times she could listen to the same music without feeling sad: "it always puts me in a mood where I'm in a little bubble. Like if I'm upset it puts me in a major bubble where I'm just completely consumed by just feeling upset. And then if I'm okay and I listen to it, then it will just make me feel not heavier but lighter and I just feel like I'm looking at everything through a window." Thus prior mood seems to influence the emotional impact that the music will have, as will the level of concentration with which she listens to it.

Participant 5 (P5) chose a love song which he described as "romantic and melancholy...dark." The piece was in a style that reminded him of music from his childhood. Although he likes most forms of music, he is particularly moved by music of his own cultural heritage. The participant has been diagnosed as suffering from anxiety and depression and he does not find it easy to put upsetting events out of his mind. He explains that listening to such music does not make him feel better. However, it gives him a sense of belonging and "it gives me a reason to be sad."

\section{Cross-Case Analysis}

Discussions with the participants fell in several broad areas: the participants' belief as to the reason for their emotional response to certain music; their purpose in choosing to listen to certain types of music; and, their experiences when listening to sad music or music expressing other negative emotions (see Table 2). These will be discussed individually below. 


\begin{tabular}{|c|c|c|c|}
\hline $\begin{array}{c}\text { Source of Emotional } \\
\text { Response }\end{array}$ & $\begin{array}{c}\text { Purposes for } \\
\text { Music Listening }\end{array}$ & Mood Regulation & $\begin{array}{c}\text { Music Evoking } \\
\text { Negative Emotions }\end{array}$ \\
\hline $\begin{array}{c}\text { Association with } \\
\text { memories }\end{array}$ & $\begin{array}{c}\text { Create a sense of } \\
\text { personal space \& } \\
\text { privacy }\end{array}$ & $\begin{array}{c}\text { Seeking mental or } \\
\text { emotional } \\
\text { stimulation or } \\
\text { arousal }\end{array}$ & $\begin{array}{c}\text { Catharsis of negative } \\
\text { emotions }\end{array}$ \\
\hline Physiological arousal & $\begin{array}{c}\text { Fill time while } \\
\text { waiting, travelling } \\
\text { or participating in } \\
\text { mundane tasks }\end{array}$ & To relax or calm & $\begin{array}{c}\text { "Company in misery"- } \\
\text { to feel one is not alone } \\
\text { in experience of } \\
\text { negative emotions }\end{array}$ \\
\hline Imagination & Social purposes & $\begin{array}{c}\text { To distract from } \\
\text { negative emotions }\end{array}$ & $\begin{array}{c}\text { To enjoy a sense of } \\
\text { hope when the music } \\
\text { resolves happily }\end{array}$ \\
\hline & Aesthetic Pleasure & $\begin{array}{c}\text { Catharsis for } \\
\text { negative emotions }\end{array}$ & $\begin{array}{c}\text { Enjoyment of } \\
\text { emotional arousal }\end{array}$ \\
\hline & Mood Regulation & $\begin{array}{c}\text { Reflecting on and } \\
\text { making sense of } \\
\text { life-events }\end{array}$ & $\begin{array}{c}\text { Reflection on life- } \\
\text { events; nostalgia; grief. }\end{array}$ \\
\hline
\end{tabular}

Table 2. Areas of Discussion in Interviews and Emergent Themes.

\section{Source of Emotional Response}

Several themes were noted in analysing the data. Association with memories was by far the most frequently mentioned mechanism which the participants believed to be the cause of their emotional response. It was mentioned both in connection with music with lyrics and without. On some occasions the music activated memories of the circumstances surrounding a prior hearing of the music; memories associated with the content of the words; because the genre of the music was the same or similar to other music connected to particular memories; or, in the case of instrumental music, because the valence matched emotions associated with a particular event or person (the 'Darling, they're playing our tune' phenomenon, Kivy, 1980).

However, another pattern observed was responses related to the concept of arousal. It seems that on many occasions, particularly with instrumental music, the participants have the impression that the transmission of emotion from the music to them is something quite immediate that does not require the presence of any mediating thoughts, ideas or mental pictures. After listening to the music in the context of the interview, several participants mentioned experiencing an instantaneous physiological response before any conscious thoughts or memories associated with the music would arise. For example,

"I don't have any pictures... after you listen this first [time] your body feels uncomfortable - [like] something in your throat, something in your stomach. And then...I think your brain understands: 'Oh, why [do] you have this feeling? Because this song is special for you.'...just like it reveals all the memories for you and after that you calm down. Then you think about something related to this song" (P1). The participants seemed to believe this to be a common experience for them when listening to music, even music that did not have any association with certain memories.

P4 also made frequent mention of responding to music that had a lot of mood changes. This is in harmony with Meyer's belief that the occurrence of unexpected events within the music generates emotional arousal (1956), or Schubert's (1996) suggestion that the listener's arousal activation level gradually increases as they become habituated to the music. Therefore arousal is maximised by music that changes.

There were also several allusions by the participants to the involvement of imagination in their emotional response. At times imagination was involved in creating a fictional scenario to accompany some instrumental music, or imagining the emotions of the composer or the performer. 


\section{Purposes for Music Listening}

To discover the reasons why individuals listen to music expressing negative emotions, it was considered important to identify their purpose in listening to music generally. Amongst the themes that developed regarding the reasons the participants listen to music were: to create a sense of personal space and privacy; to fill the time while waiting or travelling or engaging in other mundane tasks; for social purposes; and for the enjoyment of aesthetic pleasure (Table 2). The most notable pattern that emerged from the data regarding listening purposes was behaviour relating to mood regulation.

\section{MOOD REGULATION}

The data from the case studies mostly supported the theory of mood management that listening choices will be based on a desire to improve or sustain a good mood. Four of the participants used music as a deliberate instrument for improving their moods. P5 was the only one who did not appear to use music in such a way.

P2 in particular seemed very aware of mood regulation and the use of music as a tool for manipulating his emotional state: “...if there was not such a thing as music, I was wondering how I would be able to fluctuate, control my mood. But if there wasn't music I think it would be very difficult for me to do that."

The participants mentioned five specific ways in which music was used for mood regulation: to provide mental and emotional stimulation or arousal; to relax and calm; using music to distract from negative emotions; as catharsis for negative emotions; and to assist in reflecting on and making sense of life-events. These last two themes will be discussed particularly in relation to the issue of listening to sad music.

\section{AROUSAL}

The data from the cases studied here lend support to the optimal-arousal theory. Each participant mentioned listening to music in situations lacking other stimuli such as waiting, travelling on buses, or during mundane activities such as driving or doing housework. Three of them carry iPods with them for the purpose of averting boredom in such situations. Similarly, several participants discussed listening to music while studying or working on the computer. While the type of music chosen in such situations differed between individuals, the use of music to improve alertness and concentration was a common factor.

P2 felt that the energy of his preferred hip-hop music helped him to concentrate, to wake up in the mornings, to feel more optimistic about his future and more confident when going out to meet friends or doing something where he may feel unsure of himself. He states: "when I listen to this kind of music it makes me look forward towards my future, what I want to do. It makes me gain more confidence in what I'm doing at the moment and also it motivates me to have more confidence in my future, the upcoming events...And if I'm about to go outside and meet friends then I would listen to the fast-beat music."

P4 although preferring classical and instrumental music also mentions listening to such music to prepare herself when about to go out with friends, especially if she does not feel in the mood. This participant again, appeared to have deliberate mood regulation strategies involving music. She listens to music while driving and when she needs to get things done quickly at home, claiming that orchestral music with big, fast, brass sounds make her feel "more coordinated." Like P2, this participant uses music to boost her confidence prior to social events.

\section{RELAXATION AND CALMING}

Also in agreement with the optimal-arousal hypotheses is the use of music to relax and calm. Studies have found that individuals who feel over-stimulated, may use music to lower their state of arousal (Lesiuk, 2008, Labbe et al., 2007). The participants spoke about using a different style of music from what they might otherwise choose in order to help them calm down, or to help them relax and go to sleep.

P2 often changes from hip-hop to a more relaxing type of ballad or other instrumental music when he wants to fall asleep or if he needs to calm down. He also reports sometimes listening to hip-hop music when trying to go to sleep, although at a lower volume.

Similarly, P3 explained that she sometimes prefers to listen to simple music in order to counteract the "clutter" of her daily life. P4 also listens to music to calm down if she is feeling stressed. She reported 
that usually she would avoid listening to music that makes her feel too emotional and sometimes may avoid music altogether if she is feeling mentally or emotionally overwhelmed and thus is in no need of further arousal. P5 similarly avoids listening to music at all if his mind is too busy with other things.

\section{DISTRACTION}

At other times the participants use music to distract themselves from negative emotions. P2 listens to hiphop to "avoid being emotional." Similarly, P4 will avoid emotionally charged music and listen to neutral music or more complex music such as some classical pieces in an attempt to distract her mind from negative thoughts and day-to-day stresses by focusing on the technical aspects of the music.

\section{Music Evoking Negative Emotions}

The participants also discussed the reasons they sometimes listen to sad music. Several themes became apparent within the discussions. Some participants indicated that at times listening to sad music allows them to vent their own negative emotions. Aristotle similarly suggested catharsis as an explanation for the enjoyment of tragedy (Levinson, 1990). Catharsis refers to the venting of strong emotions and the belief that this leads to a beneficial lessening of tension (Rathus, 2002).

Other participants said that the music makes them feel that they are not alone in their experience of negative emotions. This is similar to the reward of "Emotional Communion" of Levinson, (1990) who argued that we benefit from feeling that we are sharing the emotions of another human being.

The theoretical literature has also offered the suggestion that people enjoy the feeling of triumph over sadness resulting from the sad music resolving happily (Levinson, 1990). Four of the participants explicitly disagreed with this. P4 however, did mention that when she feels that the music "goes somewhere and could resolve itself," it makes her hopeful. Her different response to this question may be because much of her listening is music from the Romantic period which tends to have more variability of emotion thus enhancing her awareness of the issue of resolution.

The philosophical discussions include several criticisms of the explanations of catharsis, emotional communion and emotional resolution (see Levinson, 1990, Davies, 1997, Eaton, 1982, Kivy, 1989). However such criticisms often rely on the argument that there are exceptions to these explanations, rather than pointing out fundamental flaws. An individual differences perspective, and in particular the concept of individual differences in dissociation lends plausibility to the explanations of catharsis, emotional communion and emotional resolution, as supported by the results from this study, by allowing us to understand that not all people will be attracted to music expressing negative emotions for the same reasons.

\section{AROUSAL}

Several of the participants also mentioned the arousal-type responses (as discussed above), in connection with sad music. They merely enjoyed the emotional arousal evoked by the music. This is in harmony with our earlier findings (Garrido and Schubert, 2011).

\section{REFLECTION}

Within the mood management paradigm, Zillmann (2000) has argued that sometimes people delay gratification in order to achieve some other ultimately beneficial goal. Four of the participants in this study mentioned listening to sad music for the purpose of reflecting upon events in their life. Some of the benefits obtained from engaging in such reflection included: thinking over the events in order to find positive thoughts about them; resolving issues or "making sense" of them; and, learning from past mistakes. Listening to certain kinds of music appears to help these processes although the listener may experience some form of sadness while listening.

Trapnell and Campbell (1999) argue that "reflective private self-attentiveness," the disposition and capacity to reflect and to examine the self, is a highly adaptive and psychologically healthy trait. It is distinct from ruminative tendencies which are associated with neuroticism, depression and poor selfesteem. Consistent with this idea, these participants all mentioned a point where they move away from their reflective thoughts. "But if I've got nothing else to do but music, then it just makes me think too much; and 
if I go past the stage where it's already resolved, but got nothing else to do-but keep thinking of something that's unnecessary-I will try to find something else to do" (P2).

P4 gave an extensive description of her use of music to help her "make sense" of events in her life. Even if the subject matter of the lyrics are different to her own experiences or the music has no lyrics at all, it can still be of assistance in helping her to understand her own feelings because she feels "in sync" with the emotions in the music. She seems to find it particularly useful to listen to music which goes through numerous emotional changes and describes her experience of the emotional transitions as being "like a continuous stream that came from one person, the person who wrote it, to the person who listens to it." She is not aware of any mediating thoughts when listening to such music, but appears to be intensely absorbed in an emotional journey along with the music.

P4 also demonstrated an awareness that it is not always helpful for her to listen to sad music. When she feels it will not benefit her she will listen to more neutral music, or will avoid listening to music altogether. Thus this participant appears to use sad music in two distinctive ways: (i) as a way of making sense of and dealing with daily upsetting events; (ii) as a generally absorbing and pleasing aesthetic experience when not previously in a sad mood. It seems possible that in this second situation, the participant's strong propensity for absorption and dissociation make the listening experience a pleasant and uplifting one. She appears to merely enjoy an experience of neurological arousal. Presumably, she would enjoy the same experience whether the music was happy or sad. However, if the participant is feeling sad prior to listening, then the music would intensify her sadness. Thus she avoids listening to such music when in a sad mood, unless she feels a need to think through and "make sense of" events, or to deal with her grief for a short period.

\section{NOSTALGIA}

Feelings of nostalgia were also a prominent theme in the discussions with all participants, although this is not a theme that was anticipated by a prior investigation of the literature. Nostalgia appears to be an experience that can be happy or sad or a combination of both (Zimbardo and Boyd, 1999, Wildschut et al., 2006). P1 describes listening to music that evokes sad memories, but things that are "worth it to remember." However, she avoids listening to it too often. P4 also reports indulging in nostalgia on occasion, but again, not too often.

In contrast, P5 reports that music evoking nostalgia is his preferred kind of music, and that if possible, he would listen to this music all the time. Being an immigrant to Australia, he is particularly attracted to music that reminds him of his childhood. He compares hearing such music to smelling something that reminds you of a different place and time. The nostalgia that he experiences seems to make him feel a sense of connection with the land of his birth and lessens the feelings of displacement related to his migration. However, the knowledge that his childhood can never be recreated makes the experience a sad one. The music is also connected to other painful things that he experienced in his childhood.

"I listen to this kind of music as much as I can. But it does make me a little bit blue and maybe sometimes I'd rather not do it, but I want to do it. It's almost addictive.... but I need to, so I can kind of revisit that space and time that...almost bring back that time."

This participant has been diagnosed as suffering from anxiety and depression and he does not find it easy to put upsetting events out of his mind. He explains that listening to such music does not make him feel better. However, it gives him a sense of belonging and "it gives me a reason to be sad." Other music, which does not have such strong connections to his childhood, does not evoke a similar emotional response.

This appears to be a common part of the diasporic experience (Akhtar, 1999). However, other participants in the study were migrants as well, but did not show the same strength of attraction for nostalgic music as did P5. Again it may be the case that whereas some nostalgia is a natural and normal part of the adjustment process for migrants, the focus on past memories may continue to a point where the psychological benefit to the individual is minimal. This behaviour may come under the description of rumination.

P1 in contrast, regards thinking about the past as unhealthy. Similarly, P2 prefers in general, to avoid music that will make him feel too emotional or that will make him think about the past too much, such as love songs. However, he reports using such music at times when he wants to reflect on important or negative events to try to make sense of them. 
GRIEF

Two of the participants mentioned a distinction between grief and more general feelings of sadness or low moods. Both P3 and P4 have experienced the loss of someone close to them. Sad music at times played a role in their grieving process. P4 mentioned music associated with memories of her deceased father. She felt that that music evoked a deeper level of grief than music that was sad in a more general way.

While mentioning her depression several times throughout the interview, P3 also expressed an understanding of how music can be used to either perpetuate her low moods or to help her shift out of them: "You can sort of go two ways with it. Either put on something that is depressing and can perpetuate the mood that you're in. And sometimes depending on the issue, you do want a time for grieving and feeling miserable. And then there reaches a point where you know...its time to move on, get over it, whatever." She reported that anxiety and rumination are "issues" for her and mentioned having problems with depression several times throughout the interview. However, again the participant drew a line between a healthy and natural grieving process and behaviour which steps beyond it into the maladaptive practice of rumination. "I do think it's important to at least validate how you're feeling at the time. There's probably not much point in wallowing in depression but at the same time it's a real emotion. It exists. It needs to be recognised for what it is. And sometimes things happen where if you didn't get depressed, well, that would be awful too-like a death of a close friend or family member. Stuff like that I think you do want to grieve; and it's important to grieve and music can help you do that."

Interestingly, Zisook and Schuchter (2001) argue that there is a distinction between the normal grief that occurs with bereavement and the depression that some individuals experience along with it. It may be that when bereaved individuals focus on the negative emotions that accompany grief, they have difficulty moving away from them. Nolen-Hoeksema, Parker, and Larson (1994) thus suggest that it may be the ruminative quality of their coping-style that is detrimental[1].

It seems likely that P3 has experienced both the natural grieving process and a less healthy form of rumination, but has become aware of the potential for music to be used as a tool to make her feel better. However, she still seems strongly drawn to music which makes her feel sad. This may be connected to the obviously ongoing struggle that this participant has against depression. While the participant's depression or treatment thereof was not discussed in detail during the interview, it may be the case that her listening choices would differ during an episode of depression from listening behaviour between episodes. Her lesser capacity to dissociate from the displeasure of the music or the memories that it stirs perhaps incline her to avoid sad music at times, or to indulge in the sad feelings it arouses when she is struggling against ruminative tendencies.

\section{OTHER NEGATIVE EMOTIONS}

In general, music which aroused other negative emotions tended to be avoided by the participants. P1 described avoiding music which made her feel emotionally "uncomfortable" or scared, as did P4. P3 and P4 also described music which made them angry either because it is aesthetically displeasing or because they dislike the content of the lyrics. It appears that they will both tend to avoid such music. In this case it is likely that the particular stimuli do not cause them to dissociate or to experience absorption. Therefore their displeasure nodes are not deactivated and the participants are experiencing "real" unpleasantness.

On the other hand, despite his assertions that hip-hop music did not make him more aggressive, P2 reported using it "....if I want to make myself angry or if I want to have some payback or want to try harder

to beat my goals..." His apparently contradictory answers may be because of the disapproval of fellow church members of such music as mentioned by the participant in the interview. Studies on college-age males who use heavy-metal music have found that they often listen to such music to release or unload their pent-up frustrations through the loud and intense sounds (Arnett, 1991). In this case however, P2 appears to be using the music when his aim is to bring himself into a state of high emotional arousal.

\section{CONCLUSIONS}

Part of the philosophical debate regarding emotional response to music relates to the question of how emotions are triggered in the listener and whether the emotions experienced when listening to music are "real." While in our opinion the resolution of this question is not central to understanding the question of why people may be attracted to negative emotion in music, the data in this study nevertheless revealed 
some interesting information relevant to the cognitivist/emotivist debate. The data also serve to strengthen the argument that individual differences are crucial to understanding emotional response to music including music evoking negative emotions, and that the failure to consider this may partly explain the strong differences between the arguments of philosophers on this issue.

It is proposed that individual response to sad music may fall into several patterns:

1. Individuals who prefer to listen to music that enlivens and uplifts. These may have lesser capacities for dissociation or absorption and therefore prefer to avoid music that evokes negative emotions.

2. Individuals who are strong dissociators and can therefore enjoy the neural activation of listening to music of either a negative or positive valence. Given the findings that music with the most emotional variance tends to elicit the strongest arousal, they may still demonstrate a preference for music containing passages that make them feel sad (Schubert, 1996).

3. Individuals who enjoy a capacity for absorption and dissociation - and who, due to other conditions such as the need to reflect on negative life events, deal with grief or adjust to other changes or losses in their life such as migration-may enjoy the psychological benefits of catharsis, emotional connection or emotional resolution without the usual attendant pain and displeasure.

4. Individuals with ruminative tendencies may have a lesser capacity to dissociate and will therefore experience sadness and displeasure when listening to sad music, but will nevertheless continue due to their difficulty in disengaging from negative stimuli. Alternatively, they may continue to listen because the increased arousal experienced is preferable to a more apathetic and lethargic depressed state despite the ongoing negative valence of the emotion experienced. Others may have a strong capacity for absorption, but because of the attentional bias common amongst ruminators find this absorption mostly activated by stimuli with a negative content.

P1 and P4 fit within the description of the second category. Both described themselves as having strong experiences of absorption but ruminate only to low or moderate degrees. They both appeared capable of enjoying the emotional arousal of all music regardless of valence. However, P4 demonstrated some interesting changes depending on prior mood. When affected by a sad mood, she appears to find it beneficial to use sad music for a time in order to reflect upon events or as part of the grieving process (category 3). She appears only to indulge in such reflection for a certain period of time.

The interview with $\mathrm{P} 2$ yielded more ambiguous results. Although he does not believe himself to be a daydreamer or capable of strong absorption, he does describe himself as creative and imaginative and obviously has a strong capacity to be influenced emotionally by music. Therefore he may operate in both the first and third patterns of responses mentioned above: mostly preferring energetic music, but at times using sad music to lower arousal levels and/or to reflect on events.

P3 and P5 appear to fit the fourth group. Both participants have high capacities for absorption and rumination. They both mentioned problems with depression and seem to experience a strong pull towards sad music. P3 however, demonstrated a greater awareness of the benefits of using music to break out of a negative mood. Thus at times, she used music in a way that fits the first above-mentioned pattern of response category. P5 on the other hand did not exhibit the same capacity to break out of his ruminative behaviour. His claim that he is only aware of the emotions in the music when they are of a sad, melancholy type may demonstrate an interesting interplay between a non-empathic listening style, and the bias for negatively valenced stimuli which is common to ruminators (Garrido, 2009).

As a consequence of the emergent themes in our qualitative analysis we are able to speculate a model of attraction to negative emotion in music, which can be divided into adaptive and maladaptive outcomes. Figure 1 summarises how each of the main goals of listening to sad music that emerged from the interviews could be experienced in a ruminative way, as though trapping the listener into focussing on unpleasant aspects of the music and its associations, or in an adaptive manner, leading to pleasurable, "cleansing" outcomes, or allowing the experience itself to be "enjoyed" in a state of absorption. While our conclusions are that it is possible to have several kinds of goals, and that both adaptive and maladaptive outcomes are possible, a novel aspect of this study is the identification of maladaptive attraction to negative emotion in music. Whether or not the outcome for the listener is adaptive or maladaptive may be dependent on both personality and learned response styles. Since rumination is associated with clinical depression it may well be that for some the maladaptive outcome is not a voluntary goal, but rather a result of the involuntary bias towards negative stimuli that characterises many mood disorders. This is probably in part based on the particular unbalanced brain chemistry involved in the disorder. For others it may be a learned pattern of behaviour in response to stress which continues despite the fact it does not help the listener to achieve the goal of improving his or her mood (Moulds et al., 2007). 


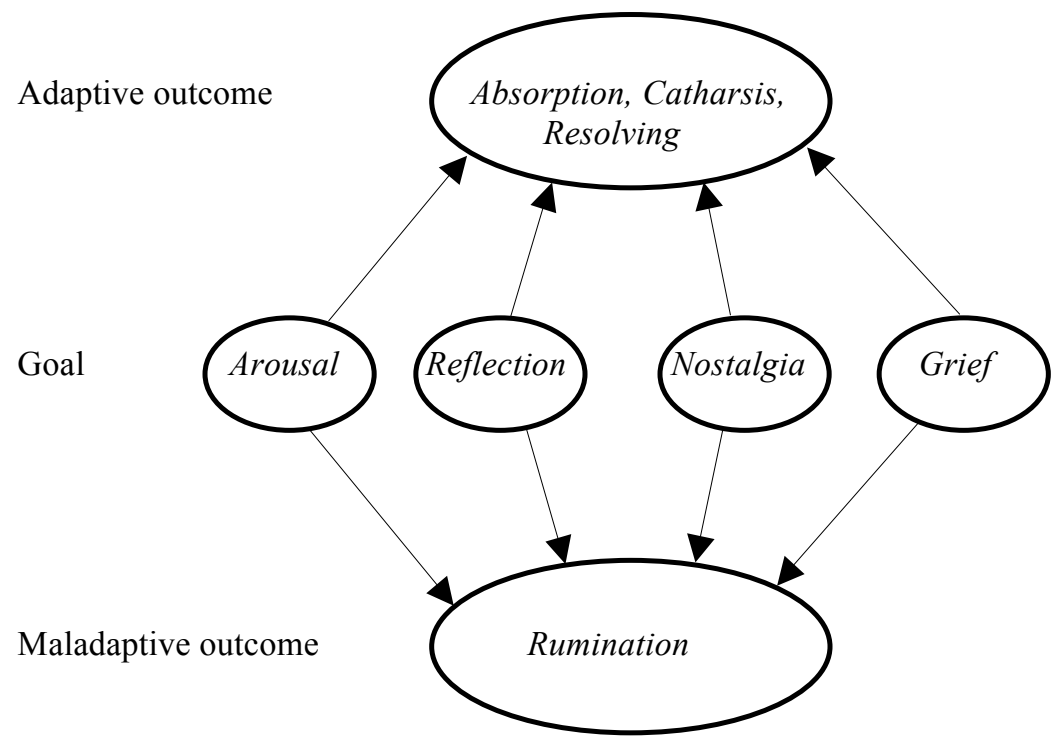

Fig. 1. A model of adaptive and maladaptive attraction to negative emotion in music.

There were some limitations to this study. Firstly, it cannot be expected that these participants would have conscious access to the mental processes involved in their behaviour. Therefore, the results of this study are not necessarily reflective of the cognitive mechanisms involved, but merely the participants' perceptions.

Although this study was based upon a small sample size it enlarges upon previous research by supporting the hypothesis that absorption and dissociation make it possible for some individuals to enjoy sad music without the usual accompanying displeasure (Garrido and Schubert, 2011). While much of the time the emotional arousal may be the aspect that attracts, prior mood may cause some to seek out sad music in order to experience particular psychological benefits such as reflecting on life-events, enjoying emotional communion, or engaging in a process of grieving in circumstances of bereavement or other major life-changes such as migration. However, there appears to be a point where the normal and healthy practices of reflection, remembering or grieving come to an end. Where most individuals would eventually move on from these processes, some individuals appear to become caught in ruminative behaviour despite the fact that this perpetuates their dysphoria.

Future studies should consider the impact of treatments for depression on listening choices amongst ruminators. It will also be important to consider whether the tendency of various individuals to ruminate is a stable response style or a transient behaviour present only during a depressive episode. Several of the participants seemed to move between categories based on conditions such as mood, or the need to deal with life events. Thus the study illustrates the variables that can influence individual cases. Future studies will therefore also need to consider the influence of prior mood in more depth, and gender related differences in music-empathy.

\section{NOTES}

[1] Nolen-Hoeksema (1991) gives quite a narrow definition of rumination, describing it as thinking repetitively and passively about one's depressive symptoms, their causes and consequences. Joorman (2005) gives a somewhat broader description of it as an involuntary focus on negative and pessimistic thoughts about one's self, the world and the future (see also Conway et al., 2000). This broader understanding of rumination may more plausibly identify the distinction between a "normal" level of grief, and the more serious forms of depression which may accompany it (Garrido, 2009). 


\section{REFERENCES}

Akhtar, S. (1999) The immigrant, the exile, and the experience of nostalgia. Journal of Applied Psychoanalytic Studies, Vol. 1 No. 2, pp. 123 - 130.

Altenmueller, E., Schurmann, K., Lim, V.K. \& Parlitz, D. (2002) Hits to the left, flops to the right: different emotions during listening to music are reflected in cortical laterisation patterns. Neuropsychologia, Vol. 40 No. 2242-2256.

Arnett, J. (1991) Adolescents and Heavy Metal Music: From the Mouths of Metalheads. Youth and Society, Vol. 23 No. 1, pp. 76 - 98.

Benjafield, J.G. (1997) Cognition. Upper Saddle River, N. J: Prentice Hall.

Berlyne, D.E. (1972) Experimental aesthetics. In: P. C. DODWELL (Ed.) New Horizons in Psychology. Oxford: Penguin.

Berridge, C.W. (2008) Noradrenergic modulation of arousal. Brain Research Reviews, Vol. 58 No. 1, pp. 117.

Braun, V. \& Clarke, V. (2006) Using thematic analysis in psychology. Qualitative Research in Psychology, Vol. 3 No. $77-101$.

Britten, N. (1995) Qualitative Research: Qualitative interviews in medical research. British Medical Journal, Vol. 311 No. 251-253.

Chamorro-Premuzic, T. (2007) Personality and individual differences. BPS Blackwell.

Chamorro-Premuzic, T. \& Furnham, A. (2007) Personality and music: can traits explain how people use music in everyday life? British Journal of Psychology, Vol. 98 No. 2, pp. 175-185.

Colombetti, G. (2005) Appraising Valence. Journal of Consciousness Studies, Vol. 12 No. 8, pp. 103 - 126.

Conway, M., Csank, P.A.R., Holm, S.L. \& Blake, C.K. (2000) On assessing individual differences in rumination on sadness. Journal of Personality Assessment, Vol. 75 No. 3, pp. 404-425.

Davies, S. (1997) Why Listen to Sad Music if it Makes One Feel Sad? In: J. ROBINSON (Ed.) Music and Meaning. New York: Cornell University Press.

Davis, M.H. (1983) Measuring individual differences in empathy: Evidence for a multidimensional approach. Journal of Personality and Social Psychology, Vol. 44 No. 1, pp. 113-126.

Duffy, E. (1962) Activation and Behavior. Oxford, England: Wiley.

Eaton, M. (1982) A Strange Kind of Sadness. Journal of Aesthetics and Art Criticism, Vol. 41 No. 1, pp. 51-63.

Eisen, M.L. \& Lynn, S.J. (2001) Dissociation, memory and suggestibility in adults and children. Applied Cognitive Psychology, Vol. No. S49-S73.

Fiske, D.W. \& Maddi, S.R. (1961) Functions of Varied Exerience. Homewood, IL: Dorsey Press. 
Fontaine, J., R. J., Scherer, K., R., Roesch, E.B. \& Ellsworth, P.C. (2007) The world of emotions is not two-dimensional. Psychologicl Science, Vol. 18 No. 12, pp. 1050-1057.

Garrido, S. (2009) Rumination and sad music: A review of the literature and a future direction. In: CATHERINE STEVENS, SCHUBERT, E., KRUITHOF, B., BUCKLEY, K. \& FAZIO, S. (Eds.) Proceedings of the 2nd International Conference on Music Communication Science (ICoMCS2). Sydney: HCSNet, University of Western Sydney.

Garrido, S. \& Schubert, E. (2010) Imagination, empathy, and dissociation in individual response to negative emotions in music. Musica Humana, Vol. 2 No. 1, pp. 55 - 80.

Garrido, S. \& Schubert, E. (2011) Individual differences in the enjoyment of negative emotion in music: A literature review and experiment. Music Perception, Vol. 28 No. 3, pp. 279-295.

Glisky, M.L. \& Kihlstrom, J.F. (1993) Hypnotizability and facets of openness. International Journal of Clinical and Experimental Hypnosis, Vol. 41 No. 112-123.

Goldberg, L.R. (1993) The structure of phenotypic personality traits. American Psychologist, Vol. 48 No. 26-34.

Joorman, J. (2005) Inhibition, rumination and mood regulation in depression. In: R. W. ENGLE, SEDEK, G., HECKER, U. V. \& MCINTOSH, D. N. (Eds.) Cognitive Limitations in Aging and Psychopathology: Attention, Working Memory, and Executive Functions. New York: Cambridge University Press.

Juslin, P.N. \& Vastfjall, D. (2008) Emotional response to music: the need to consider underlying mechanisms. Behavioral and Brain Sciences, Vol. 31 No. 559-621.

Kivy, P. (1980) The Corded Shell: Reflections on Musical Expression. Princeton University Press.

Kivy, P. (1989) Sound Sentiment. Princeton University Press.

Kivy, P. (2002) Introduction to a Philosophy of Music. Oxford: Clarendon Press.

Knobloch, S. \& Zillmann, D. (2002) Mood management via the digital jukebox. Journal of Communication, Vol. 52 No. 2, pp. 351-366.

Konecni, V.J., Brown, A. \& Wanic, R.A. (2008) Comparative Effects of Music and Recalled Life-Events on Emotional State. Psychology of Music, Vol. 36 No. 289-308.

Kreutz, G., Schubert, E. \& Mitchell, L.A. (2008) Cognitive styles of music listening. Music Perception, Vol. 26 No. 1, pp. 57-73.

Labbe, E., Schmidt, N. \& Babin, J. (2007) Coping with stress: The effectiveness of different types of music. Applied Psychophysiological Biofeedback, Vol. 32 No. 163-168.

Lesiuk, T. (2008) The effect of preferred music listening on stress levels of air traffic controllers. The Arts in Psychotherapy, Vol. 35 No. 1, pp. 1-10.

Levinson, J. (1990) Music and negative emotions. Music, Art and Metaphysics: Essays in Emotional Aesthetics. Ithaca: Cornell University Press. 
Levinson, J. (1996) Music and Negative Emotions. In: J. ROBINSON (Ed.) Music and Meaning. New York: Cornell University Press.

Litle, P. \& Zuckerman, M. (1986) Sensation seeking and music preferences. Personality and Individual Differences, Vol. 7 No. 4, pp. 575-578.

Martindale, C. (1988) Aesthetics, psychobiology, and cognition. In: F. H. HARLEY \& NEPERUD, R. W. (Eds.) The Foundations of Aesthetics, Art and Art Education.

Martindale, C. \& Moore, K. (1988) Priming, Prototypicality, and Preference. Journal of Experimental Psyxhology: Human Perception and Performance, Vol. 14 No. 4, pp. 661-670.

Meyer, L.B. (1956) Emotion and Meaning in Music. Chicago: University of Chicago Press.

Miles, M.B. \& Huberman, A.M. (1994) Qualitative Data Analysis: an Expanded Sourcebook. Thousand Oaks, CA.: Sage.

Moulds, M.L., Kandris, E., Starr, S. \& Wong, A.C.M. (2007) The relationship between rumination, avoidance and depression in a non-clinical sample. Behaviour Research and Therapy, Vol. 45 No. 251-261.

Nabi, R.L., Finnerty, K., Domschke, T. \& Hul, S. (2006) Does misery love company? Exploring the therapeutic effects of TV viewing on regretted experiences. Journal of Communication, Vol. 56 No. 689-706.

Nolen-Hoeksema, S. (1991) Responses to depression and their effects on the duration of depressive episodes. Journal of Abnormal Psychology, Vol. 100 No. 4, pp. 569-582.

Nolen-Hoeksema, S., Parker, L.E. \& Larson, J. (1994) Ruminative coping with depressed mood following loss. Journal of Personality and Social Psychology, Vol. 67 No. 1, pp. 92 - 104.

Patton, M. (1990) Qualitative Interviewing. Qualitative Evaluation and Research Methods. Newbury Park: Sage.

Rathus, S.A. (2002) Psychology in the New Millenium. Orlando: Harcourt College Publishers.

Rentfrow, P.J. \& Gosling, S.D. (2003) The do re mi's of everyday life: the structure and personality correlates of music preferences. Journal of Personality and Social Psychology, Vol. 84 No. 6, pp. 1236-1256.

Robinson, J. (1994) The expression and arousal of emotion in music. Journal of Aesthetics and Art Criticism, Vol. 52 No. 1, pp. 13-22.

Russell, J.A. (1979) Affective space is bipolar. Journal of Personality and Social Psychology, Vol. 37 No. 345-356.

Schubert, E. (1996) Enjoyment of negative emotions in music: An associative network explanation. Psychology of Music, Vol. 24 No. 18-28.

Schubert, E. (2007) The influence of emotion, locus of emotion and familiarity upon preferences in music. Psychology of Music, Vol. 35 No. 499-515. 
Sobh, R. \& Perry, C. (2006) Research design and data analysis in realism research. European Journal of Marketing, Vol. 40 No. 11/12, pp. 1194-1209.

Taylor, S.J. \& Bogdan, R. (1998) Introduction to Qualitative Research Methods: a Guidebook and Resource. New York: Wiley.

Thayer, R.E. (1978) Toward a psychological theory of multidimensional activation (arousal). Motivation and Emotion, Vol. 2 No. 1, pp. 1-34.

Thayer, R.E. (1989) The biopsychology of mood and arousal. New York: Oxford University Press.

Trapnell, P.D. (1997) Reflection-Rumination Questionnaire short forms. University of British Columbia.

Trapnell, P.D. \& Campbell, J.D. (1999) Private self-consciousness and the five-factor model of personality: distinguishing rumination from reflection. Journal of Personality and Social Psychology, Vol. 76 No. 2, pp. 284-304.

Van Ijzendoorn, M.H. \& Schuengel, V. (1996) The measurement of dissociation in normal and clinical populations: Meta-analytic validation of the Dissociative Experiences Scale (DES). Clinical Psychology Review, Vol. 16 No. 5, pp. 365-362.

Vingerhoets, A., Van Ilburg, M.A.L., Boelhouwer, A.J.W. \& Van Heck, G.L. (2001) Personality and crying. In: J. J. M. VINGERHOETS \& CORNELIUS, R. R. (Eds.) Adult crying: A biopsychosocial approach. East Sussek, UK: Brunner- Routeldge.

Westen, D. (2002) Psychology: Brain, Behaviour and Culture. New York: John Wiley \& Sons, Inc.

Wildschut, T., Sedikides, C., Arndt, J. \& Routledge, C. (2006) Nostalgia: Content, triggers, functions. Journal of Personality and Social Psychology, Vol. 91 No. 5, pp. 975-993.

Wynn, D.E. \& Williams, C.K. (2008) Critical Realism-Based Explanatory Case Study Research in Information Systems. 29th International Conference on Information Systems. Paris.

Yin, R.K. (2009) Case Study Research: Design and Methods. Thousand Oaks, C.A.: SAGE Publications.

Zentall, S.S. \& Zentall, T.R. (1983) Optimal Stimulation: A model of disordered activity and performance in normal and deviant children. Psychological Bulletin, Vol. 94 No. 3, pp. 446 - 471.

Zillmann, D. (1988) Mood management through communication choices. American Behavioral Scientist, Vol. 31 No. 3, pp. 327-340.

Zillmann, D. (2000) Mood management in the context of selective exposure theory. In: M. ROLOFF (Ed.) Communication Yearbook. Thousand Oaks, CA: Sage.

Zimbardo, P.G. \& Boyd, J.N. (1999) Putting time in perspective: A valid, reliable individual-differences metric. Journal of Personality and Social Psychology, Vol. 77 No. 6, pp. 1271-1288.

Zisook, S. \& Schuchter, S.R. (2001) Treatment of the Depression of Bereavement. The American Behavioural Scientist, Vol. 44 No. 5, pp. 782- 797. 